\title{
REGISTROS E CONTAGENS DA COMARCA DE GOIÁS (1731-1750)
}

\author{
Projeto de Pesquisa de Iniciação Científica - PIC \\ Centro Universitário de Brasília - UniCEUB \\ Orientador: Deusdedith Alves Rocha Junior - Mat: 4837-4 \\ Orientando: José Rubens de Souza Cardoso - RA: 21456932
}

\begin{abstract}
Resumo: Esta pesquisa desenvolveu, através da identificação, transcrição e análise de documentos do Arquivo Histórico Ultramarino, na cota de Goiás, a identificação de Contagens e Registros no território goiano colonial de meados do século XVIII. Considerou-se tanto a documentação que se referia diretamente aos postos fiscais, como documentos locais que tratavam indiretamente do assunto. Foram listados os postos de acordo com os anos em que foram citados e analisada a sua permanência em caso de ocorrência na documentação de anos posteriores. Em seguida, os referidos postos, Contagens e Registros, foram localizados na cartografia do mesmo período, em especial nos mapas atribuídos ao cartógrafo Tosi Colombina, onde se verificou a importância deles, de acordo com a sua presença ou ausência nos mapas. Os topônimos empregados nas instituições administrativas e fiscais de Goiás colonial permitem a investigação sobre as representações do espaço em face dos conflitos entre os sujeitos históricos nesse período (índios, portugueses e negros).
\end{abstract}

Palavras-chave: Registros e contagens; Goiás; Arquivo Histórico Ultramarino.

\section{INTRODUÇAO}

Esta pesquisa abordou a produção de conhecimento sobre o território da comarca de Goiás na primeira metade do século XVIII, a partir da distribuição territorial das contagens e registros, e as relações que elas estabeleciam com as estradas e vilas e povoados.

Através da documentação do Arquivo Histórico Ultramarino, relativos à capitania de Goiás, é possível identificar os vários postos fiscais que foram instituídos no território goiano e dimensionar a influência que fatores econômicos e políticos desempenhavam sobre eles (e eles sobre os demais aspectos da sociedade colonial goiana).

Compreendendo territorialidade como o exercício da soberania que um Estado exerce sobre uma área geográfica, podemos compreender que a produção de sentidos sobre o território através dos discursos é uma das formas de justificação dos processos de apropriação de novas terras, conforme foi adotado e praticado 
pelos movimentos colonizadores europeus desde o século $\mathrm{XV}$, e mais precisamente a partir do século XVI na América. Desse modo, ao tratar dos postos fiscais, a burocracia goiana colonial atribuía sentidos sobre eles.

A coroa portuguesa, desde fins do século XVII, passou a se organizar política e estrategicamente de um modo diferente do que fizera até então com as formas de ocupação dos interiores do território brasileiro, depois que passou a considerar a importância que a nova economia mineradora tomara para o reino. $O$ controle da entrada de portugueses (reinóis ou brasileiros), os modos como passou a tratar a questão indígena, as novas concepções territoriais (beneficiadas pelos avanços técnicos e tecnológicos da cartografia), bem como as compreensões políticas revisadas sobre os sentidos de território e de fronteira são algumas das questões que podem configurar os percursos da pesquisa histórica em decorrência das mudanças ocorridas no processo colonizador.

Ao mesmo tempo em que organiza a ocupação dos novos territórios como a instituição política de novas capitanias, a coroa portuguesa empreende um grande esforço para conhecer, mapear e exercer outras formas de controle sobre o espaço e as sociedades indígenas que ali vivem, o que se traduz em uma infinidade de documentos descritivos, avaliativos e legislativos sobre a porção territorial que se ocupa, parcial ou integralmente. E disto resultam as movimentações de grupos indígenas e as novas formas de ocupação do território, seja pelo colonizador português ou pelo negro africano em fuga da escravidão.

Mais tarde, tomada a posse do território, primeiro por portugueses, através da revisões dos acordos com o colonizador espanhol, e depois pelo Estado brasileiro ainda em torno de conflitos com índios, quilombos e remanescentes, e antigos colonos, de um lado, e as novas formas do capital, de outro, os permanentes estudos e sentidos produzidos sobre os espaços territoriais em disputa permaneceram sendo recriados como forma de justificação da gestão do Estado sobre o território.

\section{MATERIAIS E MÉTODOS}

Com o objetivo de identificar e analisar da distribuição territorial das contagens e registros da comarca de Goiás, relacionadas às vilas e povoados distribuídos pelo 
território goiano da primeira metade do século XVIII, considerando a produção de conhecimento sobre o espaço nos documentos do Arquivo Histórico Ultramarino, esta pesquisa referenciou os diversos estudos sobre a administração colonial portuguesa, em especial a capitania de Goiás, identificou os principais documentos históricos desse acervo que informam sobre as contagens e os registros no território goiano; e montou uma tabela com os dados colhidos nos documentos transcritos.

A riqueza aurífera das minas de Goiás resultou no esforço administrativo da coroa portuguesa para o controle da nova região de fluxo disperso de ocupação demográfica, resultando na proibição da abertura de novas estradas, na proibição do tráfego de rios, no pouco estímulo da agricultura e da pecuária, e acima de tudo, na fiscalização e aplicação de pesados tributos à atividade mineradora. Somente a mineração e aquilo que estivesse associado a ela era permitido e estimulado pela coroa, mas mesmo a mineração sempre esteve sujeita, como verificou Alencastre, "à capitação e censo, à venalidade dos empregados de registros e contagens, à falsificação na própria casa de fundição, ao quinto (...)." (ALENCASTRE, José Martins Pereira, 1979, p. 18).

O controle, a arrecadação e a vigilância trouxeram as casas de fundição e o contrabando, pois que este é decorrente daqueles, embora lhes tenha antecedido. Os excessos, permitidos pelos poderes conferidos aos administradores reinóis, amparavam-se na certeza da impunidade, que "nem o cipoal de leis, alvarás, cartas régias e provisões, nem os seqüestros, devassas de registros, prêmios prometidos aos delatores e comissões aos soldados puderam por freio (...)" (PALACIN, 1979, p. 49). Nestes vastos territórios, somente a diminuição e a atenção sobre os acessos sugeria ao Estado uma possibilidade de controle do processo produtivo e a aplicação dos impostos. Um vasto aparato legal, algum policiamento e a constante vigilância resultaram em relatórios, cartas e esclarecimentos sobre uma região sob constante tensão.

A correspondência com a coroa portuguesa, num momento em que o Estado primava pela sistematização racional e o controle orgânico da sua estrutura burocrática, preparando quadros da nobreza e promovendo um grande posto de informação, como foi o Conselho Ultramarino, para a manutenção dos seus espaços coloniais, foi uma evidente enxurrada de cartas, ofícios, tabelas, solicitações, relatos 
e muitos outros tipos de documentos que atravessavam o Atlântico e permitiam a constante revisão geopolítica da América portuguesa (FURTADO, 2014).

As proibições sobre as vias de acesso a Goiás foram declaradas logo nos primeiros anos da colonização mineradora. Em 1734, o tropeiro José da Costa Diogo foi penalizado com o confisco de sua mercadoria por ter trafegado de Minas Gerais para Goiás num momento em que o caminho se encontrava fechado por decreto (ROCHA JR, VIEIRA JR e CARDOSO, 2006). Somente o caminho iniciado pelas bandeiras paulistas, ligando Goiás a São Paulo e Rio de Janeiro permanecia aberto. Os acessos ao Pará e Maranhão, pelo Tocantins ou o Araguaia, os caminhos ao Piauí e à Bahia, e o percurso que dava acesso a Minas Gerais nas proximidades do rio São Francisco, ficavam interditados.

Muitos relatos em documentos do acervo do Arquivo Histórico Ultramarino, na cota de Goiás (TELES, 2001), que se referem às proibições, às justificativas de entradas por caminhos proibidos, o controle sobre rios e estradas, e mapas populacionais que evidenciam a evolução demográfica em três grandes regiões (ao sul, no entorno da sede da capitania, Vila Boa; a noroeste, na região de Pilar e Crixás; e ao norte, seguindo o rio Tocantins, na região que vai de Traíras e São José do Tocantins (atual Niquelândia) até Natividade).

Por todo o seu interior, porém, o território goiano continuou se expandindo em vilas, estradas e fazendas, construindo uma teia, uma rede que consolidava a territorialidade portuguesa, distinta das outras formas de ocupação do território brasileiro, com grandes distâncias entre os povoados e muitas estradas vicinais que tornavam as fazendas um fator importante no processo da ocupação portuguesa. Restou à coroa o controle fiscal das passagens principais através dos Registros e das Contagens, os postos estabelecidos nas saídas das minas e nos portos para fiscalizar a cobrança dos impostos e combater o contrabando.

A organização do controle fiscal sobre a produção e o comércio de bens acompanhou muito rapidamente a montagem da burocracia administrativa, antecipando ambas à confirmação do domínio português sobre as terras interiores da América. "O sistema de registros "das entradas" foi implantado em Minas Gerais a partir de 1716; em Goiás, os primeiros foram instalados em 1732; em São Paulo, a partir de 1721, nas minas do Paranapanema" (RECEITA FEDERAL, 2011). 
Havia cinco tipos de registros. Os Registros do Ouro, que fiscalizavam o transporte do minério e cobravam o quinto; os Registros de Entradas, explorado por contratadores; os Registros dos "Meios Direitos da Casa Doada", que cobravam impostos sobre animais; os Registros da Demarcação Diamantina, que combatiam o contrabando de diamantes e faziam a cobrança das "entradas"; e as Contagens, que cobravam tributos sobre animais em trânsito (RECEITA FEDERAL, 2011). Localizados em pontos de circulação regular, os caminhos clandestinos eram vigiados pela repressão, canalizando o tráfego para as áreas controladas.

Quanto aos aspectos teóricos lançaremos mão da Análise do Discurso, buscando estudar a "língua funcionando para a produção de sentidos". Desse modo, trataremos os textos considerando que a linguagem não é transparente e que procura detectar, então, como ele significa. Vendo o texto como detentor de uma materialidade simbólica própria e significativa, com o estudo do discurso, pretendese apreender a prática da linguagem, ou seja, o homem falando, além de procurar compreender a língua enquanto trabalho simbólico que faz e dá sentido, constitui o homem e sua história.

Por meio da linguagem, o homem transforma a realidade em que vive e a si mesmo. O homem constrói a existência humana, ou seja, confere-lhe sentido. E é essa capacidade do homem de atribuir, incessantemente, sentidos que promove seu constante devir, e o das coisas, que interessa à Análise do Discurso. A Análise do Discurso leva em conta o homem e a língua em suas concretudes, não enquanto sistemas abstratos. Ou seja, considera os processos e as condições por meio dos quais se produz a linguagem. Assim fazendo, insere o homem e a linguagem à sua exterioridade, à sua historicidade.

Metodologicamente analisamos os vários processos históricos que caracterizam a busca pela ocupação do território e a política de fronteiras do Brasil, no Planalto Central, especialmente no rio Tocantins. Implica em pesquisa que reúne, examina e classifica informações produzidas por relatos de viajantes. Estas são fontes relevantes para se entender os sentidos de territorialidade e fronteira nos diversos momentos, na região. É ainda uma crítica e uma interpretação das fontes para se retirar informações e se ter um melhor entendimento e esclarecimento do 
tema. E por fim, é uma interpretação, articulando as informações obtidas na crítica das fontes, tanto as cartas quanto os mapas analisados, sobre o contexto histórico.

O método histórico clássico compreende fundamentalmente o trabalho de seleção das fontes que serão tratadas na pesquisa (heurística), na verificação da validade das fontes (crítica interna), na análise dos conteúdos das fontes e as possíveis contradições e outras relações que elas possuem entre si (crítica externa), e na interpretação dos documentos, verificando o quanto as informações contidas nos documentos respondem às questões previamente levantadas (hermenêutica). No nosso caso, por se tratar de uma pesquisa documental ela também possui um caráter qualitativo, já que o exame dos documentos exige do historiador uma verificação interpretativa do seu conteúdo considerando aspectos particulares dos diversos momentos históricos, bem como de seus atores e produtores dos vestígios que sobreviveram tornados fontes. Nesta perspectiva, os sentidos produzidos pelos fatos sociais e os fenômenos históricos ganham mais importância, tendendo mais para a comparação e a explicação do que ao estudo das diferenças e da aplicação de regras (NEVES, 1996).

\section{RESULTADOS}

TABELA 1: DOCUMENTOS DO ARQUIVO HISTÓRICO ULTRAMARINO - GÓIAS QUE TRATAM DE REGISTROS E CONTAGENS

\begin{tabular}{|c|c|c|c|c|}
\hline $\begin{array}{l}\text { Doc. } \\
\text { № }\end{array}$ & Ano & Localidade & Identificação & Observações \\
\hline 79 & 1739 & Vila Boa & $\begin{array}{l}\text { AHU-Goiás } \\
\text { AHU_ACL_CU_0 } \\
08, C x .1, \bar{D} .79 .\end{array}$ & $\begin{array}{l}\text { CARTA do intendente e provedor da Fazenda Real, } \\
\text { Sebastião Mendes de Carvalho, ao rei [D. João V], } \\
\text { remetendo certidão do registro do contrato da arrematação } \\
\text { dos dízimos e do contrato das entradas do ano de } 1739 \text {. }\end{array}$ \\
\hline 395 & $\begin{array}{l}\text { [post. } \\
1748]\end{array}$ & & $\begin{array}{l}\text { AHU-Mato } \\
\text { Grosso, cx. 39, } \\
\text { doc. } 51 \\
\text { AHU_ACL_CU_O } \\
\text { 08, Cx. 5, D. } 395 \text {. }\end{array}$ & $\begin{array}{l}\text { RELAÇÃO das contagens ou registros que tem o contrato } \\
\text { das entradas nos continentes [da capitania de Goiás] e } \\
\text { suas circunferências, com a distância que há entre eles e } \\
\text { Vila Boa. }\end{array}$ \\
\hline 631 & 1754 & Vila Boa & $\begin{array}{l}\text { AHU-Goiás } \\
\text { AHU_ACL_CU_0 } \\
08, \quad \text { Cx. 10, D. } \\
631 .\end{array}$ & $\begin{array}{l}\text { OFíCIO do ouvidor-geral de Goiás, Sebastião José da } \\
\text { Cunha Soares e Vasconcelos, ao [secretário de estado da } \\
\text { Marinha e Ultramar], Diogo de Mendonça Corte Real, sobre } \\
\text { a notificação do contratador das entradas da capitania de } \\
\text { Goiás, João Martins Vieira, para não cobrar nos registros } \\
\text { das entradas os direitos das bulas da cruzada. }\end{array}$ \\
\hline
\end{tabular}




\begin{tabular}{|c|c|c|c|c|}
\hline 733 & 1755 & Vila Boa & $\begin{array}{l}\text { AHU-Goiás } \\
\text { AHU_ACL_CU_0 } \\
08, \quad \text { Cx. 12, D. } \\
733 .\end{array}$ & $\begin{array}{l}\text { CARTA do [governador e capitão-general de Goiás, conde } \\
\text { dos Arcos], D. Marcos de Noronha, ao rei [D. José], em } \\
\text { resposta à provisão sobre a ordem de não se conservar } \\
\text { nos registros do contrato das entradas para as minas e } \\
\text { suas anexas, o ouro em pó além da quantia indispensável } \\
\text { nos registros. }\end{array}$ \\
\hline 734 & 1755 & Vila Boa & $\begin{array}{l}\text { AHU-Goiás } \\
\text { AHU_ACL_CU_0 } \\
08, \quad \text { Cx. 12, D. } \\
734 .\end{array}$ & $\begin{array}{l}\text { CARTA do [governador e capitão-general de Goiás, conde } \\
\text { dos Arcos], D. Marcos de Noronha, ao rei [D. José], em } \\
\text { resposta à provisão sobre a ordem para que o governador } \\
\text { do Rio de Janeiro mande para Goiás todo o dinheiro que } \\
\text { puder; que o ouro que entrar nas Casas de Fundição de } \\
\text { Goiás seja fundido em barras miúdas e se mande para os } \\
\text { registros a fim de facilitar o comércio. }\end{array}$ \\
\hline 737 & 1755 & Vila Boa & $\begin{array}{l}\text { AHU-Goiás } \\
\text { AHU_ACL_CU_0 } \\
08, \quad \text { Cx. 12, D. } \\
736 .\end{array}$ & $\begin{array}{l}\text { OFíCIO do [governador e capitão-general de Goiás, conde } \\
\text { dos Arcos], D. Marcos de Noronha, ao [secretário de } \\
\text { estado da Marinha e Ultramar], Diogo de Mendonça Corte } \\
\text { Real, sobre a observância da ordem de Sua Majestade } \\
\text { para seguir para a Bahia somente após a chegada de seu } \\
\text { sucessor no governo de Goiás. }\end{array}$ \\
\hline 739 & 1755 & Vila Boa & $\begin{array}{l}\text { AHU-Goiás } \\
\text { AHU_ACL_CU_0 } \\
08, \quad \text { Cx. 12, D. } \\
739 .\end{array}$ & \\
\hline 741 & 1755 & Vila Boa & $\begin{array}{l}\text { AHU-Goiás } \\
\text { AHU_ACL_CU_0 } \\
08, \quad \text { Cx. 12, D. } \\
741 .\end{array}$ & $\begin{array}{l}\text { OFíclO do intendente e provedor da Fazenda Real de } \\
\text { Goiás, Anastácio da Nóbrega, ao [secretário de estado da } \\
\text { Marinha e Ultramar], Diogo de Mendonça Corte Real, } \\
\text { remetendo a despesa anual da Provedoria e Casas de } \\
\text { Fundição de Vila Boa e São Félix, com os ordenados e } \\
\text { mais despesas dos registros. }\end{array}$ \\
\hline 990 & 1760 & Vila Boa & $\begin{array}{l}\text { AHU-Goiás } \\
\text { AHU_ACL_CU_0 } \\
08, \quad \text { Cx. 17, D. } \\
990 .\end{array}$ & $\begin{array}{l}\text { OFíclo do [governador e capitão-general de Goiás], João } \\
\text { Manuel de Melo, ao [governador e capitão-general do Rio } \\
\text { de Janeiro] conde de Bobadela, [Gomes Freire de } \\
\text { Andrade], sobre ter sido a capitania de Goiás socorrida } \\
\text { com prata vinda de Vila Rica para o uso dos Registros e } \\
\text { cadinhos para as Casas de Fundição. }\end{array}$ \\
\hline 1010 & 1760 & Lisboa & $\begin{array}{l}\text { AHU-Rio } r \\
\text { Janeiro, cx. 67, } \\
\text { doc. 33 } \\
\text { AHU_ACL_CU_0 } \\
\text { 08, Cx. 17, D. } \\
1010 .\end{array}$ & $\begin{array}{l}\text { CONSULTA do Conselho Ultramarino, ao rei D. José, } \\
\text { sobre a carta do intendente do arraial de São Félix, António } \\
\text { Luís Lisboa, a respeito de como agiu com dois réus que } \\
\text { ficaram pronunciados na devassa acerca do extravio do } \\
\text { ouro e solicitando que se declare se será conveniente } \\
\text { colocar um Registro na estrada por onde o extravio foi feito. }\end{array}$ \\
\hline 1014 & 1760 & Rio de Janeiro & $\begin{array}{l}\text { AHU-Goiás } \\
\text { AHU_ACL_CU_0 } \\
08, \quad \text { Cx. 17, D. } \\
1014 .\end{array}$ & $\begin{array}{l}\text { OFÍCIO (minuta) do [governador do Rio de Janeiro, conde } \\
\text { de Bobadela, Gomes Freire de Andrade], ao [governador e } \\
\text { capitão-general de Goiás], João Manuel de Melo, sobre a } \\
\text { esperança de Ihe enviar notícias da corte e agradecendo a } \\
\text { ajuda recebida acerca do atraso em que encontrou os } \\
\text { rendimentos da capitania do Rio de Janeiro e Casa da } \\
\text { Moeda. }\end{array}$ \\
\hline 1098 & 1762 & Vila Boa & $\begin{array}{l}\text { AHU-Goiás } \\
\text { AHU_ACL_CU_0 } \\
08, \quad \text { Cx. 18, D. }\end{array}$ & $\begin{array}{l}\text { CARTA do [governador e capitão-general de Goiás], João } \\
\text { Manuel de Melo, ao rei [D. José], sobre o cumprimento das }\end{array}$ \\
\hline
\end{tabular}




\begin{tabular}{|c|c|c|c|c|}
\hline & & & 1098. & $\begin{array}{l}\text { ordens para se conservar e estabelecer um Registro no } \\
\text { caminho do Duro, por ser o mais cômodo aos viandantes, e } \\
\text { de fazer cessar o conflito de jurisdição entre as } \\
\text { Intendências de Vila Boa e São Félix. }\end{array}$ \\
\hline 1213 & 1764 & Vila Boa & $\begin{array}{l}\text { AHU-Goiás } \\
\text { AHU_ACL_CU_0 } \\
08, \quad \text { Cx. 20, D. } \\
1213 .\end{array}$ & $\begin{array}{l}\text { OFícIO do [governador e capitão-general de Goiás], João } \\
\text { Manuel de Melo, ao secretário de estado [da Marinha e } \\
\text { Ultramar], Francisco Xavier de Mendonça Furtado, sobre a } \\
\text { possibilidade de se estabelecer um Registro no caminho de } \\
\text { Goiás para Mato Grosso, visando conter o extravio do ouro } \\
\text { para aquela capitania, em virtude das grandes distâncias e } \\
\text { da região estar ocupada pelos índios Caiapós. }\end{array}$ \\
\hline 1248 & 1764 & Vila Boa & $\begin{array}{l}\text { AHU-Goiás } \\
\text { AHU_ACL_CU_0 } \\
08, \quad \text { Cx. 20, D. } \\
1248 .\end{array}$ & $\begin{array}{l}\text { OFÍCIO do ouvidor-geral intendente e provedor da Fazenda } \\
\text { Real de Goiás, desembargador António José de Araújo e } \\
\text { Sousa, sobre a informação do tenente Damião José de Sá } \\
\text { Pereira, acerca da desordem ocorrida no Registro do Duro, } \\
\text { distrito da Intendência de São Félix, devido à falta de } \\
\text { moeda de prata, e queixando-se do tesoureiro da Casa de } \\
\text { Fundição de São Félix, Diogo de Gouveia Osório e Castro. }\end{array}$ \\
\hline 1337 & 1764 & Vila Boa & $\begin{array}{l}\text { AHU-Goiás } \\
\text { AHU_ACL_CU_0 } \\
08, \quad \text { Cx. 20, D. } \\
1248 .\end{array}$ & $\begin{array}{l}\text { OFíCIO do ouvidor-geral intendente e provedor da Fazenda } \\
\text { Real de Goiás, desembargador António José de Araújo e } \\
\text { Sousa, sobre a informação do tenente Damião José de Sá } \\
\text { Pereira, acerca da desordem ocorrida no Registro do Duro, } \\
\text { distrito da Intendência de São Félix, devido à falta de } \\
\text { moeda de prata, e queixando-se do tesoureiro da Casa de } \\
\text { Fundição de São Félix, Diogo de Gouveia Osório e Castro. }\end{array}$ \\
\hline 1496 & 1768 & Vila Boa & $\begin{array}{l}\text { AHU-Goiás } \\
\text { AHU_ACL_CU_0 } \\
08, \quad \text { Cx. 24, D. } \\
1496 .\end{array}$ & $\begin{array}{l}\text { CARTA do [ouvidor-geral] e provedor da Fazenda Real de } \\
\text { Goiás, desembargador António José de Araújo e Sousa, ao } \\
\text { rei [D. José], sobre o rendimento do contrato das entradas } \\
\text { e remetendo relação e mapa dos Registros, o respectivo } \\
\text { rendimento de cada um, os gêneros de que se pagaram os } \\
\text { direitos e os produtos que entraram por cada um dos } \\
\text { Registros. }\end{array}$ \\
\hline 1500 & 1768 & Vila Boa & $\begin{array}{l}\text { AHU-Goiás } \\
\text { AHU_ACL_CU_0 } \\
08, \quad \text { Cx. 24, D. } \\
1500 .\end{array}$ & $\begin{array}{l}\text { CARTA do [ouvidor-geral] e provedor da Fazenda Real de } \\
\text { Goiás, desembargador António José de Araújo e Sousa, ao } \\
\text { rei [D. José], sobre não corresponder os rendimentos das } \\
\text { contagens, com as despesas da Provedoria da Fazenda } \\
\text { Real de Goiás; a necessidade de se cobrar em Goiás o } \\
\text { direito das mercadorias vindas pelo caminho de Minas } \\
\text { Gerais e acerca do contrato das entradas que sem } \\
\text { arrematante desde } 1765 \text {, tem sido administrado pela } \\
\text { Fazenda Real. }\end{array}$ \\
\hline 1518 & 1768 & Vila Boa & $\begin{array}{l}\text { AHU-Goiás } \\
\text { AHU_ACL_CU_0 } \\
08, \quad \text { Cx. 24, D. } \\
1518 .\end{array}$ & $\begin{array}{l}\text { CARTA do [ouvidor-geral] e provedor da Fazenda Real de } \\
\text { Goiás, desembargador António José de Araújo e Sousa, ao } \\
\text { rei [D. José], remetendo relação e mapa do que rendeu } \\
\text { cada uma das contagens da capitania de Goiás e os } \\
\text { gêneros que por elas entraram em } 1767 \text {. }\end{array}$ \\
\hline 1685 & 1772 & Vila Boa & $\begin{array}{l}\text { AHU-Goiás } \\
\text { AHU_ACL_CU_0 } \\
08, \quad C x .26, \quad \text { D. } \\
1685 .\end{array}$ & $\begin{array}{l}\text { OFíCIO do [governador e capitão-general de Goiás, barão } \\
\text { de Mossâmedes], José de Almeida Vasconcelos [de } \\
\text { Soveral e Carvalho], ao [secretário de estado da Marinha e } \\
\text { Ultramar], Martinho de Melo e Castro, sobre as cartas } \\
\text { apresentadas pelos ex-governadores acerca dos guardas } \\
\text { do registro do rio das Velhas que limita as capitanias de } \\
\text { Goiás e Minas Gerais, e a disputa territorial entre as ditas } \\
\text { capitanias. }\end{array}$ \\
\hline
\end{tabular}




\begin{tabular}{|c|c|c|c|c|}
\hline 1722 & 1773 & Vila Boa & $\begin{array}{l}\text { AHU-Goiás } \\
\text { AHU_ACL_CU_0 } \\
08, C x .27, \text { D. } \\
1722 .\end{array}$ & $\begin{array}{l}\text { OFÍCIO do [governador e capitão-general de Goiás, barão } \\
\text { de Mossâmedes], José de Almeida Vasconcelos [de } \\
\text { Soveral e Carvalho], ao [secretário de estado da Marinha e } \\
\text { Ultramar], Martinho de Melo e Castro, sobre a prata da } \\
\text { permuta conduzida ao Registro por soldados e outros } \\
\text { condutores que trouxeram carregações para Goiás } \\
\text { passando pela capitania de São Paulo, e os direitos das } \\
\text { entradas cobrados em prejuízo do comércio da dita } \\
\text { capitania. }\end{array}$ \\
\hline 1756 & 1774 & Vila Boa & $\begin{array}{l}\text { AHU-Goiás } \\
\text { AHU_ACL_CU_0 } \\
08, \quad C x .27, \quad \text { D. } \\
1756 .\end{array}$ & $\begin{array}{l}\text { OFíCIO do [governador e capitão-general de Goiás, barão } \\
\text { de Mossâmedes], José de Almeida Vasconcelos [de } \\
\text { Soveral e Carvalho], ao [secretário de estado da Marinha e } \\
\text { Ultramar], Martinho de Melo e Castro, sobre a forma } \\
\text { imprópria com que os Registros foram estabelecidos em } \\
\text { Goiás, provocando extravios em prejuízo da Fazenda Real. }\end{array}$ \\
\hline 1854 & 1776 & Vila Boa & $\begin{array}{l}\text { AHU-Goiás } \\
\text { AHU_ACL_CU_0 } \\
\text { 08, Cx. 28, D. } \\
1854 .\end{array}$ & $\begin{array}{l}\text { CARTA da Junta da Administração da Fazenda Real de } \\
\text { Goiás, ao rei [D. José], sobre o recebimento de uma carta } \\
\text { da Junta da Fazenda Real de Minas Gerais, informando } \\
\text { que aquela capitania arrematara o contrato de todas as } \\
\text { minas unindo o contrato das capitanias em um só; e } \\
\text { solicitando se restitua à Fazenda Real de Goiás os direitos } \\
\text { das entradas das fazendas que entraram para Goiás pelo } \\
\text { Registro de Matias Barbosa, cobrando-se em Goiás, este } \\
\text { rendimento, pelo contrato das entradas. }\end{array}$ \\
\hline 1946 & 1778 & Vila Boa & $\begin{array}{l}\text { AHU-Goiás } \\
\text { AHU_ACL_CU_0 } \\
08, \quad \text { Cx. 30, D. } \\
1946 .\end{array}$ & $\begin{array}{l}\text { OFÍCIO do [governador e capitão-general de Goiás, Luís } \\
\text { da Cunha Menezes], ao [secretário de estado da Marinha e } \\
\text { Ultramar], Martinho de Melo e Castro, sobre as primeiras } \\
\text { medidas governamentais tomadas logo após sua posse; a } \\
\text { ordem dada ao secretário de governo para escrever cartas } \\
\text { circulares aos fiéis dos registros, aos cabos da sua } \\
\text { guarnição e ao intendente da Casa de Fundição de São } \\
\text { Félix para cumprirem com as suas obrigações e } \\
\text { executarem as ordens prescritas pelo seu antecessor, } \\
\text { [barão de Mossâmedes, José de Almeida Vasconcelos } \\
\text { Soveral e Carvalho], e acerca de estar regulando seu } \\
\text { governo pelas instruções recebidas quando ainda se } \\
\text { encontrava na Bahia. }\end{array}$ \\
\hline 2012 & 1781 & Traíras & $\begin{array}{l}\text { AHU-Goiás } \\
\text { AHU_ACL_CU_0 } \\
\text { 08, Cx. 32, D. } \\
\text { 2012. }\end{array}$ & $\begin{array}{l}\text { OFÍCIO do [capelão] João de Almeida Cardoso, sobre a } \\
\text { devassa, mandada tirar pelo Bispo do Rio de Janeiro ao } \\
\text { vigário-geral, José Simões da Mota e Medeiros, o qual se } \\
\text { encontra foragido, e solicitando auxílio para que se vigie } \\
\text { todas as contagens e Registros para aprisionar o dito } \\
\text { vigário. }\end{array}$ \\
\hline 2228 & 1787 & Vila Boa & $\begin{array}{l}\text { AHU-Goiás } \\
\text { AHU_ACL_CU_0 } \\
08, \quad \text { Cx. 36, D. } \\
\text { 2228. }\end{array}$ & $\begin{array}{l}\text { OFíCIO do [governador e capitão-general de Goiás], } \\
\text { Tristão da Cunha Meneses, ao [secretário de estado da } \\
\text { Marinha e Ultramar] D. Rodrigo de Sousa Coutinho, sobre } \\
\text { retorno de uma bandeira com um número reduzido de } \\
\text { índios Xavantes conquistados, e a necessidade de se } \\
\text { construir um Registro no rio Tocantins, a fim de se evitar o } \\
\text { extravio de ouro em pó. }\end{array}$ \\
\hline 2327 & $\begin{array}{l}\text { ant. } \\
1789\end{array}$ & Goiás & $\begin{array}{l}\text { AHU-Goiás } \\
\text { AHU_ACL_CU_0 } \\
08, \quad \text { Cx. 37, D. } \\
2327 .\end{array}$ & $\begin{array}{l}\text { REQUERIMENTO de Paulo José de Aquino, seu pai } \\
\text { Tomás João Rufo e Miguel da Costa, à rainha [D. Maria I], } \\
\text { solicitando certidões das arrobas de ouro que deram } \\
\text { entrada na Casa de Fundição de Vila Boa, e três certidões } \\
\text { do Registro Geral das mercês para serem reformadas. }\end{array}$ \\
\hline 2412 & ant. & Goiás & $\begin{array}{l}\text { AHU-Goiás } \\
\text { AHU_ACL_CU_0 }\end{array}$ & $\begin{array}{l}\text { REQUERIMENTO do capitão José Pereira Bandeira, do } \\
\text { arraial do distrito de Natividade, à rainha [D. Maria I], }\end{array}$ \\
\hline
\end{tabular}




\begin{tabular}{|c|c|c|c|c|}
\hline & 1794 & & $\begin{array}{l}\text { 08, Cx. 39, D. } \\
\text { 2412. }\end{array}$ & $\begin{array}{l}\text { solicitando ordem para que as suas carregações possam } \\
\text { passar com guias nos registros por onde entrarem, visto } \\
\text { assim poder pagar os direitos das entradas em qualquer } \\
\text { dos arraiais por onde chegarem. }\end{array}$ \\
\hline 2415 & 1794 & Vila Boa & $\begin{array}{l}\text { AHU-Goiás } \\
\text { AHU_ACL_CU_0 } \\
08, \text { Cx. 39, D. } \\
2415 .\end{array}$ & $\begin{array}{l}\text { CARTA do capitão-mor de Vila Boa, António de Sousa } \\
\text { Teles e Meneses, à rainha [D. Maria I], sobre o novo } \\
\text { método de pagamento dos direitos das entradas em Goiás, } \\
\text { imposto pelo seu governador e capitão-general, [Tristão da } \\
\text { Cunha Meneses], contra os votos e protestos do } \\
\text { procurador da Fazenda Real, obrigando os negociantes de } \\
\text { escravos, fazendas e molhados a pagarem os ditos direitos } \\
\text { à vista, nas contagens postas nos limites da capitania; a } \\
\text { diminuição do rendimento dos contratos das entradas pela } \\
\text { falta de providências do dito governador e solicitando } \\
\text { decisão justa, referente ao novo método, em benefício dos } \\
\text { negociantes daquela capitania. }\end{array}$ \\
\hline 2717 & $\begin{array}{l}\text { post. } \\
1804\end{array}$ & Vila Boa & $\begin{array}{l}\text { AHU-Goiás } \\
\text { AHU_ACL_CU_0 } \\
\text { 08, Cx. 47, D. } \\
\text { 2717. }\end{array}$ & $\begin{array}{l}\text { AUTO de uma Provisão sobre as atividades produtivas e } \\
\text { financeiras da Fazenda Real ,realizadas na capitania de } \\
\text { Goiás. } \\
\text { Anexos: } 22 \text { docs., (inclui mapas da receita e despesa, } \\
\text { balanços da Fazenda Real, tabelas dos gêneros que } \\
\text { entram pelos Registros e Contagens, despesa da folha } \\
\text { militar, mapa do rendimento do quinto de } 1752 \text { a } 1803 \text {, } \\
\text { relação do ouro que entrou na Casa de Fundição de Vila } \\
\text { Boa em } 1801 \text { e } 1802 \text {, tabela das lotações dos ofícios de } \\
\text { Justiça de } 1772 \text {, a avaliação dos mesmos ofícios de } 1798 \text {, } \\
\text { e mapa do rendimento e despesa do subsídio literário de } \\
1774 \text { a 1803). }\end{array}$ \\
\hline 2908 & 1807 & Lisboa & $\begin{array}{l}\text { AHU-Goiás } \\
\text { AHU_ACL_CU_0 } \\
08, \quad \text { Cx. 52, D. } \\
\text { 2908. }\end{array}$ & $\begin{array}{l}\text { AVISO do [secretário de estado da Marinha e Ultramar], } \\
\text { visconde de Anadia, [João Rodrigues de Sá e Melo], ao } \\
\text { [conselheiro do Conselho Ultramarino], visconde da Lapa, } \\
\text { [Manuel de Almeida e Vasconcelos Soveral de Carvalho da } \\
\text { Maia Soares de Albergaria], sobre a representação dos } \\
\text { habitantes do Julgado do Desemboque, do sertão de Araxá } \\
\text { e Salitre, e desertos do rio Grande e Paranaíba, capitania } \\
\text { de Goiás, solicitando a isenção do pagamento das } \\
\text { contagens do sertão dos limites da capitania de Minas } \\
\text { Gerais com a de Goiás, pela existência de dúvidas quanto } \\
\text { a pertencer este sertão a esta ou àquela capitania. }\end{array}$ \\
\hline
\end{tabular}

TABELA 2:TABELA DE REGISTROS E CONTAGENS DA CAPITANIA DE GOIÁS

\begin{tabular}{|l|l|}
\hline \multicolumn{1}{|c|}{ Instituição } & \\
\hline \multirow{4}{*}{ Registros } & BANDEIRINHA \\
\cline { 2 - 2 } & BOA VISTA \\
\cline { 2 - 2 } & TRAÍRAS \\
\cline { 2 - 2 } & ARRAIAS \\
\cline { 2 - 2 } & ARREPENDIDOS \\
\hline & FERREIROS \\
\hline & INSUA \\
\hline & LAGOA FEIA \\
\hline & OLHOS D'ÁGUA \\
\hline & SALINAS \\
\hline & SANTA MARIA \\
\hline & SANTA RITA \\
\hline
\end{tabular}




\begin{tabular}{|c|c|}
\hline & $\begin{array}{l}\text { SÃO BARTOLOMEU } \\
\text { SÃO BERNARDO } \\
\text { SÃO DOMINGOS } \\
\text { SÃO JOÃO DAS DUAS BARRAS } \\
\text { SÃO MARCOS } \\
\text { TAGUATINGA } \\
\text { CAMINHO DE CUIABÁ } \\
\text { CUIABÁ } \\
\text { DESEMBOQUE } \\
\text { DURO } \\
\text { RIO DAS ÉGUAS } \\
\text { RIO DAS VELHAS } \\
\text { RIO GRANDE } \\
\text { TOCANTINS }\end{array}$ \\
\hline Contagens & $\begin{array}{l}\text { Contagem da Chapada da Natividade } \\
\text { Contagem da Chapada de São Félix } \\
\text { Contagem da Conceição } \\
\text { Contagem da Extrema } \\
\text { Contagem da Natividade } \\
\text { Contagem das Almas } \\
\text { Contagem de Arraias } \\
\text { Contagem de Cavalcante } \\
\text { Contagem de Itaoca } \\
\text { Contagem de Muquém } \\
\text { Contagem de Pontal } \\
\text { Contagem São Bartolomeu } \\
\text { Contagem São Felix } \\
\text { Contagem São João das Três barras } \\
\text { Contagem Tocantins } \\
\text { Contagem Carmo } \\
\text { Contagem do Descoberto Amaro Leite } \\
\text { Contagem do Descoberto Ouro Podre } \\
\text { Contagem do Príncipe }\end{array}$ \\
\hline Casas de Fundição & $\begin{array}{l}\text { Casa de Fundição - CAVALCANTE } \\
\text { Casa de Fundição - GOIÁS } \\
\text { Casa de Fundição - MEIA-PONTE } \\
\text { Casa de Fundição - SÃO FÉLIX }\end{array}$ \\
\hline Intendências do Ouro & $\begin{array}{l}\text { Intendência do Ouro - VILA BOA } \\
\text { Intendência do Ouro - GOIÁS } \\
\text { Intendência do Ouro - SANTANA } \\
\text { Intendência do Ouro - SÃO FÉLIX } \\
\text { Intendência do Ouro - TOCANTINS } \\
\text { Intendência do Ouro - TRAÍRAS }\end{array}$ \\
\hline Oficinas Monetárias & Oficina Monetária - GOIÁS \\
\hline
\end{tabular}




\begin{tabular}{|l|l|}
\hline Provedorias da & Provedoria da Fazenda Real - GOIÁS \\
\cline { 2 - 2 } Fazenda Real & Provedoria da Fazenda Real - MEIA PONTE \\
\hline & \\
\hline $\begin{array}{l}\text { Superintendências das } \\
\text { Minas }\end{array}$ & Superintendência das Minas - GOIÁS \\
\cline { 2 - 2 } & Superintendência das Minas - MEIA-PONTE \\
\hline
\end{tabular}

\section{REFERÊNCIAS}

ABREU, João Capistrano. Caminhos antigos e Povoamento do Brasil. S,L., 1960, $2^{\circ}$ edição.

ALENCASTRE, José M. Pereira de. Anais da Província de Goiás - 1863. Brasília:

Ed. Gráfica Ipiranga, 1979.

BURKUE, Peter. A escrita da História. Novas Perspectivas. Ed. Unesp.

GOFF, Le. A nova História. Ed. Martins Fontes.

CARDOSO, Ciro Flamarion \& VAINFAS, Ronaldo (Org.) Domínios da História.

BERTRAN, Paulo. História da Terra e do Homem no Planalto Central. Brasília: Solo, 1994.

BERWANGNER, Ana Regina; LEAL, João Eurípedes Franklin. Noções de Paleografia e Diplomática. 3. Ed. Rev. E ampl. - Santa Maria: Ed. Da UFSM; 2008.

FURTADO, J. F. Dom João V e a década de 1720: novas perspectivas na ordenação do espaço mundial e novas práticas letradas. In FRAGOSO, J. e GOUVÊA, M. de F. O Brasil colonial: 1720-1821. V.3. Rio de Janeiro: Civilização Brasileira, 2014.

LACOSTE, Yves. A Geografia - Isso serve em primeiro lugar, para fazer a guerra. 12 ed. São Paulo: Papirus, 2006.

ORLANDI, Eni Pulcinelli. Discurso e Leitura. 8ํㅡ. Ed. São Paulo, Cortez, 2008.

NEVES, José Luís. Pesquisa qualitativa - características, usos e possibilidades. Caderno de Pesquisas em Administração. São Paulo, V.1, N.3, 2ํs semestre/1996.

PALACIN, Goiás 1722/1822. Estrutura e conjuntura numa capitania de minas.

Goiânia: Oriente, 1979.

RECEITA FEDERAL. Memória Receita Federal - Registros

http://www.receita.fazenda.gov.br/Memoria/administracao/reparticoes/colonia/registro s.asp\# (acessado em 26/02/2011).

ROCHA Jr, Deusdedith Alves; VIEIRA Jr, Wilson e CARDOSO, Rafael Carvalho C. Viagem pela estrada real dos Goyazes. Brasília: Paralelo 15, 2006.

TELES, José Mendonça (org.). Catálogo de Verbetes do Manuscrito Avulsos da Capitania de Goiás existentes no Arquivo Histórico Ultramarino, Lisboa-Portugal. Goiânia: Sociedade Goiana de Cultura, Institutos de Pesquisas e Estudos Históricos do Brasil-Central, 2001. 
